Journal of Advanced College of Engineering and Management, Vol. 6, 2021

\title{
DETERMINISTIC AND PROBABILISTIC ANALYSIS OF DASDHUNGA SOIL SLOPE ALONG NARAYANGARH-MUGLING ROAD SECTION
}

\author{
Saurav Shrestha ${ }^{1}$, Dr. Indra Prasad Acharya ${ }^{2}$, Dr. Ranjan Kumar Dahal ${ }^{3}$ \\ ${ }^{1}$ Research Student, Masters in Geotechnical Engineering, Pulchowk Campus \\ Email: Address: 072msg817saurav@pcampus.edu.np \\ ${ }^{2}$ Associate Professor, Coordinator, Master Program in Geotechnical Engineering, Pulchowk Campus, TU \\ ${ }^{3}$ Associate Professor, GeoDisaster Research Center, Central Department of Geology, TU
}

(GeoStudio, 2005)

\begin{abstract}
Instability of slopes is usually governed by a combination of intrinsic and extrinsic factors. The inherent variability of parameters make the problem probabilistic rather than a deterministic one. This research deals with evaluation of stability of slopes with the calculation of the factor of safety of Dasdhunga soil slope along Narayangarh- Mugling road section under different rainfall conditions through the use of coupled finite element and limit equilibrium method in GeoStudio and the determination of probability of failure by sliding, modeled as infinite slopes by using Monte Carlo simulation in R-Studio. Mean, standard deviation, minimum and maximum values of the parameters like- friction angle, cohesion and unit weight were computed from eight samples of the slope. The pore water pressure developed and its corresponding statistical data for different rainfall conditions were computed from FEM based SEEP/W simulation. The above parameters are assumed to follow truncated normal probability distribution function and the geometric parameters like height and slope angle are regarded as constant parameters. It was observed that the safety factors for theslopeis low in high intensity-low duration rainfalls and the probability of failure is high. The tendency to fail increases as the return period of rainfall increases and viceversa. Sensitivity analysis performed in both deterministic and probabilistic methods showed that friction angle is the most sensitive.
\end{abstract}

Keywords: Infinite slopes, Rainfall, Finite Element Method, Limit Equilibrium, Monte Carlo Simulation, GeoStudio, R-Studio

\section{Introduction}

A global data set of fatalities from non-seismically triggered landslides that resulted in loss of life between 2004 and 2010 AD shows that, 2620 fatal landslides were recorded worldwide during the $7 \mathrm{yr}$ period of the study, causing a total of 32,322 recorded fatalities. The majority of human losses occur in Asia, especially along the Himalayan Arc [1].In conventional approach to slope stability analysis and design, the shear strength parameters, slope geometry, external loads and pore water pressures are assigned some specific unvarying values. But precise knowledge of material properties is lacking whilst, mean material properties with some uncertainty are known. In probabilistic method, the possibility that, values of shear strength and other parameters may vary is considered, providing a means of evaluating the degree of uncertainty.

Especially, the Middle and High mountains of Nepal are the areas having the highest chances of slope failure. The area of study in this research is Dasdhunga slope with in Narayangarh- Mugling road section which falls in Bharatpur Metropolitan City, Chitwan district of Nepal, with Tanahu on the North West. When the slopes along Narayangarh- Mugling road section were excavated and the start of monsoon of 2017 became considerably active, the problem of debris became serious and violent as that 
of 23 June 2017. The area experienced heavy rainfall in monsoon season which kept the debris flowing down and obstructing roads[2]. Information and photograph of the selected site are given as follows:

Table 0.1 Location features of Dasdhunga slope

\begin{tabular}{|l|l|l|l|}
\hline \multicolumn{4}{|l|}{ Location Name- Dasdhunga } \\
\hline Chainage & $15+600$ & Elevation $(\mathrm{m})$ & 200 \\
\hline Northing $(\mathrm{m})$ & 3075346 & Dip Direction & $170^{\circ}$ \\
\hline Easting $(\mathrm{m})$ & 248825 & Slope Angle & $40^{\circ}$ \\
\hline
\end{tabular}

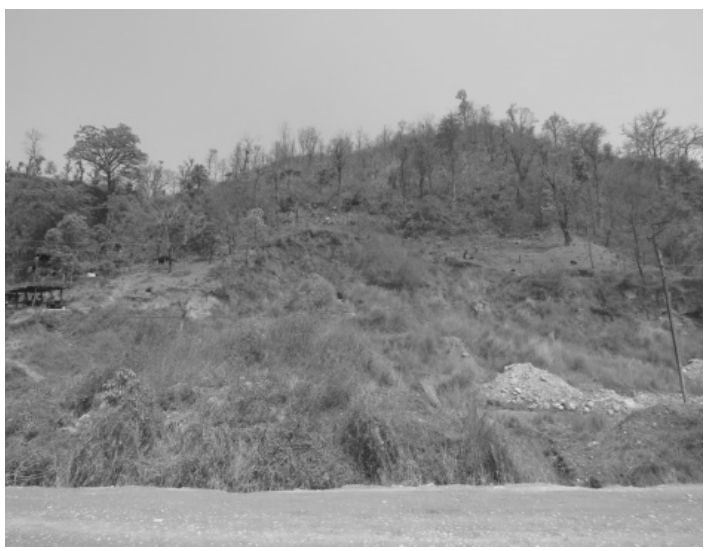

Fig 0.1 Dasdhunga Slope

The General objective of the research work is to study the natural slope along Narayangarh- Mugling road section in deterministic and probabilistic terms considering it as infinite slope. This research work will help in the assessment of such landslide prone areas and mitigation of future damages.

\section{Literature Review}

\subsection{Landslide and Rainfall}

The area of road section consists of two major geological structures, namely, Devachuli Thrust (DT) and Main Boundary Thrust (MBT). Devachuli Thrust can be recognized about $5.97 \mathrm{~km}$ south from Ghumaune and MBT can be recognized about $2.82 \mathrm{~km}$ north of Jugedi along the road. Similarly, Jalbire Syncline can be observed that passes about $1 \mathrm{~km}$ south of Jalbire[3]. Timilsina and Dahal[4] have discussed about the landslide hazard in Mugling road and found that most of the roadside slope failures during torrential rainfall events were shallow translational slides that converged towards the main valleys leading to catastrophic debris flows at Narayanghat- Mugling road.

Dahal and Hasegawa [5] described the regional aspects of rainfall thresholds for landslides in the Himalaya. Generally, a coarse-grained soil slope fails in saturated conditions as high permeability of the soil leads to the development of positive pore water pressure. However, in fine grained soils, there is no rapid development of pore water pressure owing to poor permeability. Rather, failure in fine- 
grained soil slope occurs in an unsaturated state because of decrease in shear strength due to loss of matric suction. Also, shallow failures are due to increased positive pore water pressure, whereas reduction in matric suction leads to deep-seated failures. Studies have shown that both deep and shallow seated landslides can be triggered by rainfall, but deep seated landslides are triggered by moderate intensity long duration rainfall, while shallow landslides are usually triggered by short duration, intense precipitations [6].

\subsection{Limit Equilibrium Method and Finite Element Method}

The slope stability analysis is performed with the LEM based assumptions about the sliding surface shape. Simplicity and reduced number of parameters have made this method popular. MorgensternPrice method has been applied as a LEM method in SLOPE/W in GeoStudio software in this research. However, it assumes safety factors to be constant along the failure surface and shear strength of the materials along the potential failure surface is governed by linear (Mohr-Coulomb) theory.

SEEP/W analysis is a finite element software where the porewater pressures at every nodes are calculated at certain time steps, whereas SLOPE/W works according to a Limit Equilibrium model. Coupled SEEP/W-SLOPE/W analyses have been employed successively to evaluate stability conditions of embankments and slopes.

\subsection{Probabilistic Method}

Johari and Javadi[7] did a reliability assessment of infinite slope stability using the jointly distributed random variables method considering the parameters like cohesion, friction angle and unit weight to follow normal distribution. Ejezie[8] pointed out that the actual distribution of pore water pressure is beta and gamma distribution. But it can be approximated as normal distribution as this also gives results without loss of accuracy.

\subsection{Infinite Soil Slope}

Dahal et al. [6] assessed the failure characteristics of rainfall induced shallow landslides in granitic terrains of Shikoku island of Japan analytically by using the Duncan's equation for infinite slope. The study was done to employ a standard method of stability analysis of translational slides during extreme rainfall conditions.

The equation proposed by Duncan et al. [9] is

$\mathrm{FOS}=\frac{C}{\gamma H \sin \beta \cos \beta}+\left\{1-\frac{P W P}{\gamma H(\cos \beta)^{\wedge} 2}\right\} \frac{\tan \Phi}{\tan \beta} \ldots$

In this research work, natural soil slope is studied considering it as infinite slope. Morgenstern Price method was used in the Geo-Studio software with the application of far field boundary condition whereas, Duncan's infinite slope equation was used to assess the probability of failure.

\subsection{Monte Carlo Simulation}

Kim et al [10] used Monte Carlo simulation to analyze several modes of rock slope failure. In order to perform the probability analysis using the Duncan's infinite slope equation, the stochastic parameters used are: internal friction angle, cohesion, unit weight and porewater pressure. Similarly, the deterministic parameters are: soil slope thickness and slope angle. 


\subsection{PEM, FOSM and Normality Test}

The Generalised Point Estimate Method can be used for rapid calculation of the mean and standard deviation of factor of safety which depends upon random behavior of input variables. Hoek[11] discussed the application of this technique to the analysis of surface crown pillar stability while Pine [12] has applied this technique to the analysis of slope stability and other mining problems. First Order Second Moment (FOSM) Method is a probabilistic method to determine the stochastic moments of a function with random input variables. This method takes no account of the form of the probability density function, describing the random variables using only their mean and standard deviation [13].The Shapiro-Wilk test is a test of normality in frequentist statistics. The null-hypothesis of this test is that the population is normally distributed. Thus, on one hand, if the p value is less than the chosen alpha level, then the null hypothesis is rejected and there is evidence that the data tested are not normally distributed and viceversa[14].

\section{Methodology}

The tasks involved during research work are as follows:

\subsection{Desk Study}

Published reports, journals, field manuals and established theories related to the study were collected from different sources and studied in detail which was the basis for site investigation. Topographical map of the study area (scale $=1: 25,000$ ) published by the Survey Department, GON was studied. The study provided some preliminary information to formulate the schedule and general route for the field and laboratory work.

\subsection{Field Study}

During reconnaissance survey, the study area was selected and the information collected during the desk study was verified which helped to schedule the detail field study. Survey work was carried out usinggps and total station to determine the location and profile of slope respectively. Slope face was divided into grids (for convenience, 8 horizontal grids were made, meaning 8 rows were imaginarily constructed in the slope). Depending upon the width of slope, the number of columns could vary. Similarly some field tests- field soil identification, moisture content and hydraulic conductivity tests were performed in the field and disturbed soil samples were collected from 8 locations of the same slope.

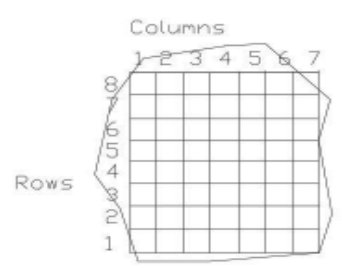

Fig 0.2Schematic illustration of the imaginary Fig 0.1 Schematic Illustration of the finite element grid assumed at face of soil slone

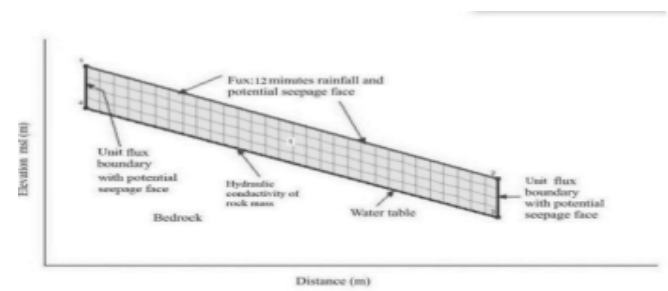

model used in SFF.P/W 


\section{Sampling, Insitu Tests and Laboratory Tests}

Sampling was done by using a cylindrical sampler through disturbed sampling technique. Field Moisture content was determined by using the guidelines in manual (AASHTOT265).To find the saturated hydraulic conductivity of soil, single ring in filtrometer test was conducted at each site where soil samples were taken using the manual provided by the United States Department of Agriculture, Natural Resources Conservation Service (USDA- NRCS). Sieve analysis was done to find out the particle size gradation of all the soil samples by following the AASHTOT88-93 testing procedure. Density bottle was used for determination of specific gravity of soil solids following the procedure mentioned in IS 2720 part-2, 1980. To find out the Atterberg's limits, AASHTOT89-90 and T90-96 testing procedures were followed. All the above mentioned tests were performed in the soil lab of HCOE, Lalitpur. Direct shear tests were conducted following the code- IS 2720 part 13-1986. All of the specimen were sheared in drained conditions under $0.5 \mathrm{~kg} / \mathrm{cm}^{2}\left(49.05 \mathrm{kN} / \mathrm{m}^{2}\right), 1 \mathrm{~kg} / \mathrm{cm}^{2}\left(98.1 \mathrm{kN} / \mathrm{m}^{2}\right)$, and $1.5 \mathrm{~kg} / \mathrm{cm}^{2}\left(147.15 \mathrm{kN} / \mathrm{m}^{2}\right)$ of normal stress. Direct Shear Test was done in the Heavy lab of IOE, Pulchowk Campus under strain controlled conditions.

\subsection{Rainfall Data Analysis}

Rainfall data of the last 17 years was obtained from the Department of Hydrology and Meteorology. On using Thiessen polygon, it was identified that Devghat rain gauge station (Station No- 450) affected slope location the most. In order to find out the amount of cumulative maximum rainfall that occured in 1 day, 2day, 3 day, 5 day, 10 day in each years of the last 17 years history, a coded program was written in R-Studio. Using Gumbels extrapolation method, the maximum rainfall that could occur in above mentioned days for a return period of 2, 5, 10, 25, 50, 75 and 100 years were calculated.

\subsection{Model Parameters and Stability analysis}

Thickness of soil layer ranges from 1.5 to $3.5 \mathrm{~m}$ which was done by visual inspection at the side of slope. Hence an average depth of $2.5 \mathrm{~m}$ was selected. The slope was modeled by adopting slopes generated from SWDTM and AutoCAD. Contact between soil and rock was considered to be geometrically planar. Geotechnical parameters presented in Table 0.1 were used in the models. Modeling of transient pore water pressure and slope stability was done with SEEP/W and coupled in SLOPE/W. Volumetric water content and hydraulic conductivity functions were obtained from curves derived using grain size distribution function provided in Geo Studio (2012) as well as by inputting the analytically calculated values of saturated water content and actual measured values of hydraulic conductivity. For simulations, the monsoon rainfall event of 1 day max, 2 day max, 3 day max, 5 day max and 10 day max was divided into 120, 240, 360, 600 and 1200 time steps of 12 min length and seepage into the soil were simulated in SEEP/W. For the boundary conditions, a transient flux function was applied to the nodes along the ground surface whereas the element size was taken as $1 \mathrm{~m}$. SEEP/W does not possess infinite slope option hence, in order to apply infinite slope condition, an unit flux boundary condition equal to the hydraulic conductivity of soil along with potential seepage face was assigned to the upslope and down slope vertical faces of the model. A semi transient flux condition with hydraulic conductivity of fractured metamorphic rock was imposed at the lower boundary of each simulation. The complete layout of model is shown in Fig 0.1. Rate of evaporation was not considered in this modeling. The transient seepage analysis was used as a parent analysis in the pore water pressure condition for this model and the model was started. The result from SEEP/W was then coupled into SLOPE/W to obtain the factor of safety. 


\subsection{Generation of random data from probabilistic parameters}

Since, 8 soil samples were collected from a single slope, there were 8 sets of such parameters. Those data were used to calculate the mean, standard deviation, minimum and maximum values. A truncated normal distributed pattern was created where the minimum and maximum values of the distribution was taken as (mean- $3 \mathrm{x}$ standard deviation) and (mean $+3 \mathrm{x}$ standard deviation) of each parameter covering up $99.8 \%$ of data in the distribution. Using the random data generation tool in a programing software called R-Studio, 1 million data of each of the parameters were generated.

\subsection{Calculation of Probability of failure}

Data generated from above process were used to calculate the factor of safety. Hence a total of 1 million Factor of safety was generated in each simulation. To find out if the data of factor of safety followed a Normal distribution or not, Shapiro Wilk Normality test was performed. After performing the normality test, the mean and standard deviation of those data were calculated. The calculated number of factor of safeties whose magnitude is less than 1 was counted and divided by the total number of factor of safeties computed i.e. 1 million. This would give the probability of failure. The frequency of the computed factor of safety was plotted to give a probability distribution as well. This work was repeated to calculate the probability of failure for varying rainfall conditions.

\subsection{Sensitivity Analysis in GeoStudio and R-Studio}

Parameters like friction angle, cohesion, unit weight and porewater pressure were varied from their mean values one at a time keeping other parameters constant and the models in Geostudio were operated to give the sensitivity analysis. The parameters were varied from 10 to $50 \%$ of the mean value in both the positive and negative directions. In R Studio, each parameters were varied by $30 \%$ of the mean value.

\section{Results and Discussion}

Results from sieve analysis and consistency limit test yielded that the soil is silty sand, some reflecting properties of well gradedness and some poor gradedness. Factor of safety and probability of failure calculation and sensitivity analysis are all discussed here.

Rainfall for different Days maximum, Time Step and Intensity used. The maximum possible rainfall and rainfall intensity that would occur in 1 day, 2day, 3day, 5day and 10day for return periods of 2, 5, $10,25,50,75,100$ years computed by Gumbel's extrapolation method are presented in

Fig 0.1 and Fig 0.2 respectively. 


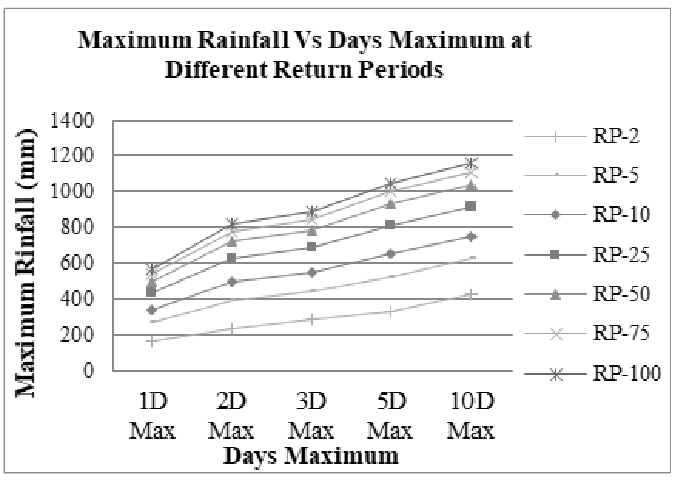

Fig 0.1Maximum Rainfall occurring at varying varying

days of different return periods

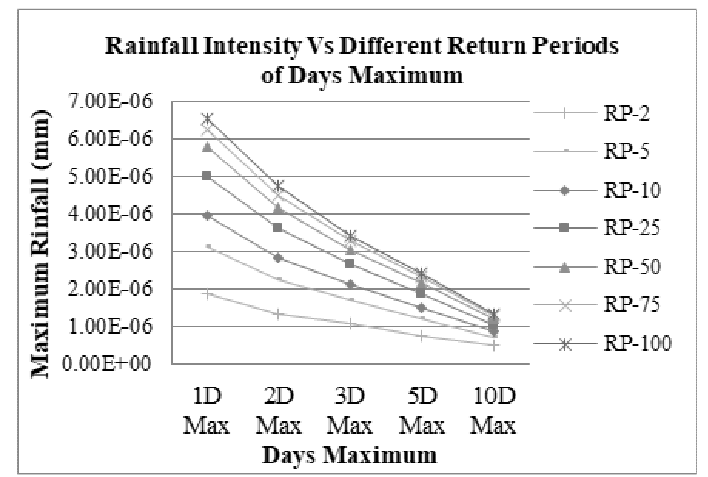

Fig 0.2 Intensity of Rainfall occurring at days of different return periods

The data show that the trend of rainfall for different return periods for different days do not occur linearly, because it doesnot rain uniformly throughout for a long period of time. In contrast, as the amount of rainfall increases over a length of time, the intensity decreases. The difference of rainfall amount in between 2years and 100years return period for 1 day (i.e. $403 \mathrm{~mm}$ ) and the rainfall amount for same return periods for 10 days (i.e. $729 \mathrm{~mm}$ ) is incremental, but not so drastic, however, the intensity difference is decremental and that too is hugely reduced from 1 day to a 10 days period. The rainfall intensity of all the return periods seem to converge at a point as the days-rainfall increases meaning intensity of rainfall decreases over a long length of time however great the return period might be.

\subsection{Summary of Parameters used in SEEP/W and SLOPE/W}

The simulation of slope models requires the engineering, index and hydraulic properties which are written below. Coefficient of volume change and hydraulic conductivity for rockmasswere taken from the literature [15]. Saturated Water Content were calculated analytically and Saturated hydraulic Conductivity were measured using single ring infiltrometer in the field. Geotechnical parameters were taken from each of the 8 grids of soil slope whereas the porewater pressure data were taken from the slice bases in GeoStudio for 35 rainfall conditions for each slope. The number of slices in possible slip surface varies according to the rainfall condition and is very high in number. Hence the original data cannot be accommodated here rather, only the computed mean, standard deviation, maximum and minimum values are shown. Below presented is the porewater pressure for 1- day of 100 year return period rainfall condition.

Table 0.1 Essential parameters used for Dasdhunga soil slope

\begin{tabular}{|c|c|c|c|c|c|c|c|c|c|c|c|}
\hline $\begin{array}{c}\text { S } \\
\text { No. }\end{array}$ & \multirow{2}{*}{$\mathrm{R}$} & \multirow{2}{*}{$\mathrm{C}$} & $\mathrm{D}_{10}$ & $\mathrm{D}_{60}$ & $\mathrm{LL}$ & $\begin{array}{c}\text { Saturated } \\
\mathrm{K}_{\mathrm{x}}\end{array}$ & $\begin{array}{c}\text { Saturated } \\
\mathrm{WC}\end{array}$ & $\phi$ & $\mathrm{C}$ & $\gamma$ & $\mathrm{PWP}$ \\
\cline { 4 - 13 } & & & $\mathrm{mm}$ & $\mathrm{mm}$ & $\%$ & $\mathrm{~m} / \mathrm{sec}$ & $\%$ & degrees & $\mathrm{kN} / \mathrm{m}^{2}$ & $\mathrm{kN} / \mathrm{m}^{3}$ & $\mathrm{kN} / \mathrm{m}^{2}$ \\
\hline 1 & 1 & 4 & 0.106 & 1.976 & 34.406 & $3.30 \mathrm{E}-06$ & 25.955 & 32.158 & 1.675 & 17.058 & - \\
\hline
\end{tabular}




\begin{tabular}{|c|c|c|c|c|c|c|c|c|c|c|c|}
\hline 2 & 2 & 2 & 0.120 & 2.341 & 31.099 & $4.18 \mathrm{E}-06$ & 24.700 & 31.581 & 2.589 & 17.347 & - \\
\hline 3 & 3 & 2 & 0.109 & 2.455 & 33.467 & $3.19 \mathrm{E}-06$ & 26.548 & 33.292 & 2.132 & 16.335 & - \\
\hline 4 & 4 & 5 & 0.099 & 2.416 & 34.117 & $3.59 \mathrm{E}-06$ & 25.098 & 33.663 & 1.675 & 16.952 & - \\
\hline 5 & 5 & 2 & 0.090 & 2.274 & 31.181 & $3.08 \mathrm{E}-06$ & 23.624 & 31.774 & 2.284 & 16.817 & - \\
\hline 6 & 6 & 1 & 0.099 & 2.326 & 31.746 & $3.29 \mathrm{E}-06$ & 24.311 & 31.581 & 2.437 & 17.270 & - \\
\hline 7 & 7 & 3 & 0.090 & 1.979 & 34.267 & $3.80 \mathrm{E}-06$ & 23.219 & 34.031 & 1.371 & 17.733 & - \\
\hline 8 & 8 & 4 & 0.101 & 2.278 & 33.774 & $3.12 \mathrm{E}-06$ & 24.426 & 32.917 & 2.132 & 17.453 & - \\
\hline & \multicolumn{2}{|c|}{ Mean } & 0.102 & 2.255 & 33.007 & $3.44 \mathrm{E}-06$ & 24.735 & 32.625 & 2.037 & 17.121 & -0.473 \\
\hline & \multicolumn{2}{|c|}{$\Sigma$} & & & & & & 0.979 & 0.422 & 0.431 & 1.246 \\
\hline & \multicolumn{2}{|c|}{ Minimum } & & & & & & 29.689 & 0.769 & 15.828 & -4.211 \\
\hline & \multicolumn{2}{|c|}{ Maximum } & & & & & & 35.560 & 3.304 & 18.414 & 3.264 \\
\hline
\end{tabular}

Co-efficient of Volume compressibility, $\mathrm{m}_{\mathrm{v}}=0.00001 / \mathrm{kPa}$

Hydraulic Conductivity of Rockmass, $K_{\text {Rockmass }}=4 \mathrm{E}-08 \mathrm{~m} / \mathrm{sec}$

\subsection{Analysis of SEEP/W and SLOPE/W}

Out of 35 different simulations done in Dasdhunga soil slope, rainfall of smaller days of any year return period seems the most intriguing. The factor of safety for 2 year-1day rainfall is 1.07 which means the slope is safe and it is due to some negative porewater pressure due to initial rainfall. When more extreme rainfall of $270 \mathrm{~mm}$ per 24 hour (i.e. 5year-1day) occurs, porewater pressure is increased which seems to reach a critical state with a factor of safety of 0.962 . And when the slope is hit with even more extreme rainfall intensity reaching at $341 \mathrm{~mm}$ per 24 hour (i.e. 10 year- 1day), the slope enters an unstable state with safety factor of 0.90 . Reduction of matric suction and increase of porewater pressure decreases the shear strength parameters which is the reason for failure. The factor of safety for higher days of rainfall tends to increase very slightly, which might be an indication of the development of drainage characteristics in the slopes. Below are the result of simulation done in SLOPE/W for several rainfall conditions. 


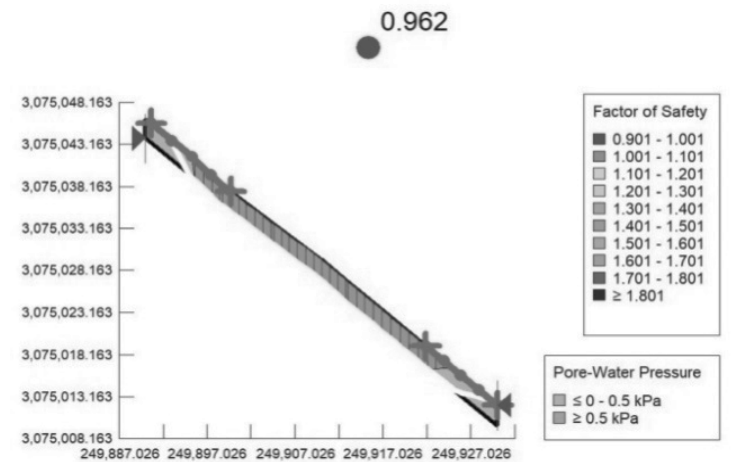

Figure 0.3 Result of analysis of Dasdhunga soil slope at 1 -day maximum rainfall of 5 year return period

Probabilistic analysis was done in R-Studio by using Monte Carlo simulation in the infinite slope equation proposed by Duncan. The probability of failure for different rainfall conditions is presented in Figure 0.5 .

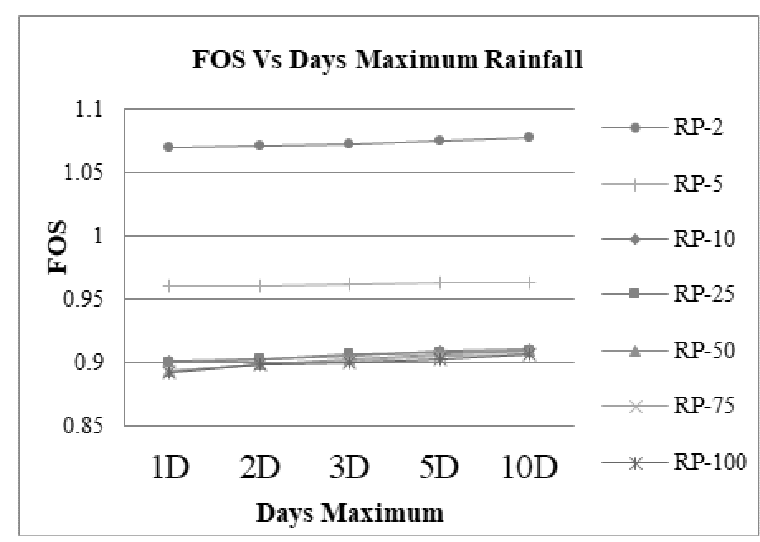

Figure 4.4

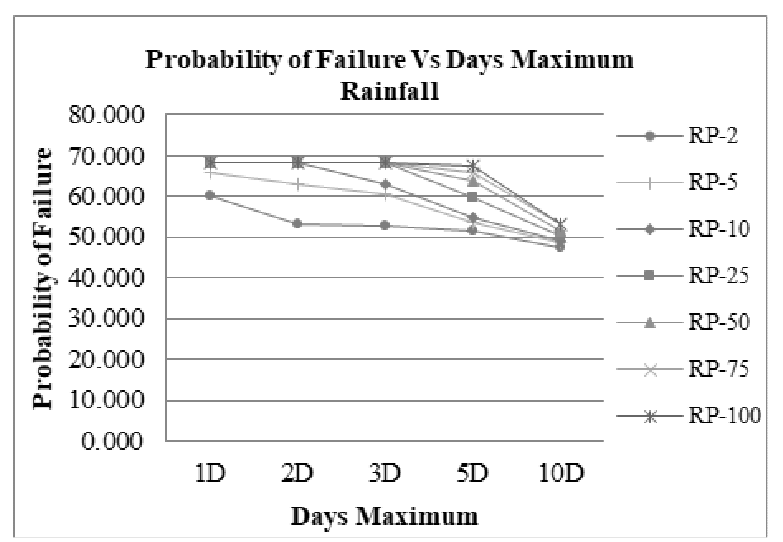

Figure 4.5

Figure 0.4 Plot of Factor of Safety of Dasdhunga at different rainfall conditions

Figure $0.5 \mathrm{P}$ robability of sliding of Dasdhunga soil slope under different rainfall conditions

The graph indicates that the probability of failure for 1 day rainfall is highest for $10,25,50,75$ and 100 years return periods and lowest for 2 year return period. 5 year return period rainfall is close to the other higher rainfall group indicating that the 5 year return period rainfall is approaching the critical condition. On moving right, the rainfall of 10 year return period starts dropping from 3day maximum rainfall. The probability of failure of rainfall of the highest return period starts falling later than the rainfall of lower return periods indicating when the intensity of rainfall is higher, the probability of failure is higher, because such rainfall can create positive porewater pressure quickly and reduce the shear strength parameters and vice versa. 

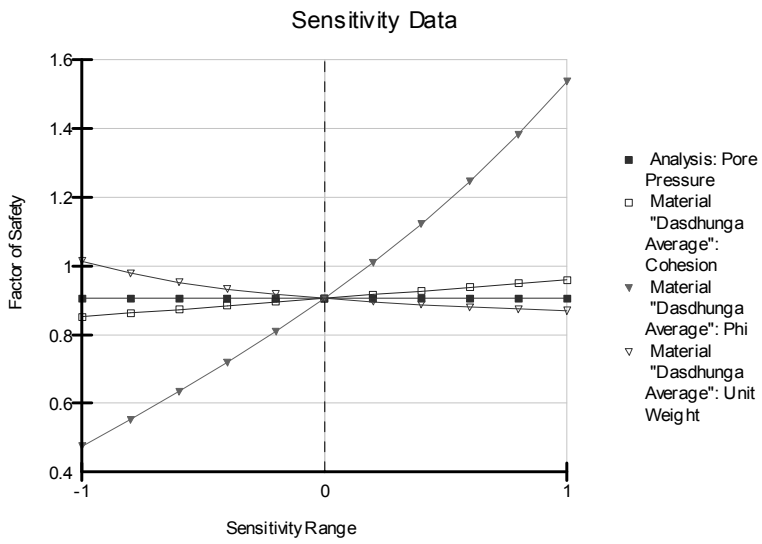

Fig 0.6 Sensitivity analysis of parameters of Dasdhunga parameters in

soil slope using GeoStudio

function

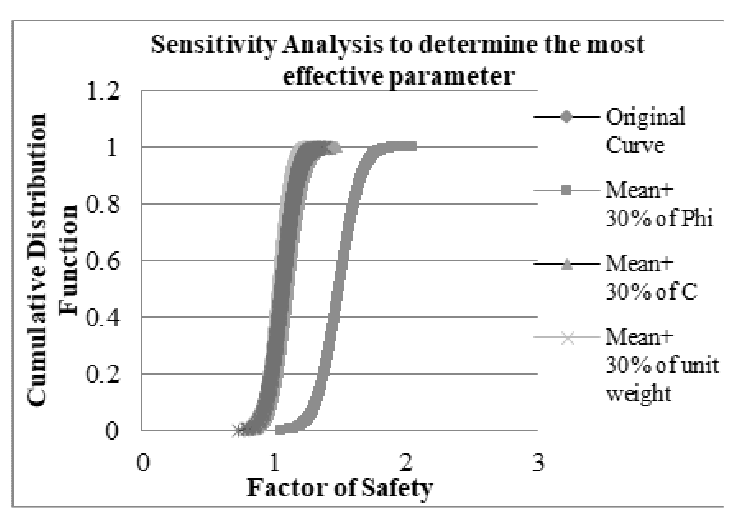

Fig 0.7Sensitivity analysis of all

terms of cumulative distribution

\section{Verification}

\subsection{Verification with Literature}

The results from Geostudio models provided that Dasdhunga soil slope would be critical if a 24 hour rainfall of 5 year return period (i.e. $270 \mathrm{~mm}$ ) would occur. Studies have shown that rainfall triggered landslides in coarse grained soils occur due to intense precipitation in short duration [6].In southern hills of Kathmandu, Dahal et al. [16] observed that the debris slides and flows occurred when 24 hour rainfall exceeded $260 \mathrm{~mm}$. So the results of this study are supported by the literature. Dahal et al. [6] formulated a relationship of intensity and duration of rainfall that would initiate landslide in Nepal Himalayas which is, $\mathrm{I}=73.9 \mathrm{D}^{-0.79}$, where $\mathrm{I}$ is the intensity of rainfall $(\mathrm{mm} / \mathrm{hr})$ and $\mathrm{D}$ is the duration of rainfall (hr). It provides that a 24 hour rainfall period would require a rainfall intensity of $1.66 \mathrm{E}-6$ $\mathrm{m} / \mathrm{sec}$. And the rainfall intensity corresponding to the $270 \mathrm{~mm}$ rainfall is $3.12 \mathrm{E}-6 \mathrm{~m} / \mathrm{sec}$ which further supports the claim. Zhou et al. [17] have assessed the probability of failure in a soil slope of dominantly sand with respect to normalized intensity of rainfall at varying groundwater depths. Probability of failure seems more for the rainfall with higher normalized intensity and vice-versa.

\subsection{Verification of result of MonteCarlo Simulation with other methods}

Shapiro-Wilk normality test was done in SPSS software which resulted in a significance value of 0.81 . For a group of data to follow a normal distribution, the significance value by Shapiro Wilk Test should exceed 0.05 , which it does [14]. Mean value and standard deviation of the factor of safety for 100 year10d rainfall in Dasdhunga slope were computed by MCS, PEM and FOSM methods and compared. 
Table 0.1 Mean Factor of safety and standard devation computed by MCS, PEM and FOSM method

\begin{tabular}{|l|l|l|}
\hline Method & Mean FOS & Standard Deviation \\
\hline MonteCarlo & 0.99650 & 0.05512 \\
\hline Point Estimate & 0.99648 & 0.05584 \\
\hline First Order Second Moment & 0.99603 & 0.05577 \\
\hline
\end{tabular}

The data in the Table 0.1 are written upto 5 decimal places only to ascertain the position of discrepancy.

\section{Conclusion and Recommendations}

\subsection{Conclusion}

Soil characteristics and heavy monsoon rainfall are found to be the main contributing parameters for slope instability. It is observed that Dasdhunga soil slope becomes critical under a 24 hour maximum rainfall of 5 year return period (i.e. $270 \mathrm{~mm}$ ). Failure in these soil slopes is due to the increase in porewater pressure from negative to zero and positive values which indicate this soil slope tends to fail at the boundary of unsaturated and saturated condition. Comparing the stability related to lesser duration (i.e. 1 day) to that of higher duration (i.e. 10 days) in every return period rainfall condition, the stability improves i.e.factor of safety increases and probability of failure decreases. This must be due to the fact that the uniform intensity of rainfall when occurs over a larger duration is always less than the uniform intensity of rainfall occuring over a shorter intense duration. The other reason for improvement of stability of slope might be due to the improved regulation of drainage over a longer duration. The permeability of the soil is in the range of $\left(10^{-6}-10^{-5} \mathrm{~m} / \mathrm{s}\right)$ which is a moderate type, so it is responsible for regulation of drainage. The sensitivity analysis of parameters showed that the factor of safety is influenced the most by the friction angle followed by cohesion, unit weight and porewater pressure for these slopes.

\subsection{Recommendations}

The deterministic and probabilistic analyses were done considering the slope as infinite slopes. Study could be done considering it as finite slope. Variation of only geotechnical parameters and rainfall intensity is assessed in this work considering geometry as a constant parameter. Hence, variation of geometry could be done in future work.

\section{Acknowledgement}

I wish to express my sincere appreciation to my supervisors Dr. Indra Prasad Acharya and Dr. Ranjan Kumar Dahal for their guidance and critical suggestion throughout the research work. I am thankful to the Department of Civil Engineering, Central Material Testing Laboratory, Heavy Lab, IOE, Pulchowk and Himalaya College of Engineering, Chyasal for assisting me with the academic and lab works. I am also thankful to my colleagues from Geotechnical Engineering, my geologist colleagues Shankar Pantha and KabitaMaharjan and fellow engineer- Er. Rasu Shrestha. 


\section{References}

1. Petley, David. (2012). "Global patterns of loss of life from landslides." Geology. 40. 927-930. 10.1130/G33217.1.

2. Roads, Department of. Improvement of Narayanghat- Mugling Road; "Report on Identification of Potential Slope Failure Area and Their Remedial Measures”. 2017. (IDA CREDIT No. 5273NEP).

3. "Depositional environment of the Lesser Himalayan Rocks in the Muglin-Bandipur area", Central Nepal. Paudyal, Kabi Raj. s.1. : Journal of Nepal Geological Society, 2012, Vol. 44. 89-98.

4. "Landslide hazard in Mugling Road.” Timilsina M., Dahal R. K. 2013, Int. J. Lsld. Env., pp. 105106.

5. Dahal RK, Hasegawa S. "Representative rainfall thresholds for landslides in the Nepal Himalaya. Geomorphology.”2008;100(3-4):429-43.

6. Dahal RK, Hasegawa S, Nonomura A, Yamanaka M, Dhakal S, Paudyal P. "Predictive modelling of rainfall-induced landslide hazard in the Lesser Himalaya of Nepal based on weights-ofevidence." Geomorphology [Internet]. 2008;102(3-4):496-510.

7. Johari A, Javadi AA. "Reliability assessment of infinite slope stability using the jointly distributed random variables method." Sci Iran [Internet]. 2012;19(3):423-9.

8. Ejezie SU. "Probabilistic nature of cyclic load pore pressure in cohesive soil." Struct Saf. 1987;4(3):169-78.

9. Duncan JM, Buchilgnani AL, DeWet M (1987) “An Engineering Manual for Slope Stability Studies." Virginia Polytechnic Institute and State University, Blacksburg, Virginia. 80 pp.

10. Kim, Hyung-Sik et al. "Application Of Monte Carlo Techniques To Slope Stability Analyses." (1978). Proc. $19^{\text {th }}$. US. Symp. Rock Mech: 28- 39

11. Hoek, E. 1989. “A Limit Equilibrium Analysis of Surface Crown Pillar stability.” Proc. Int. Conf. on Surface Crown Pillars Active \& Abandoned Metal Mines Timmins, pp.3-13.

12. Pine. R.J. 1992. "Risk analysis design applications in mining geomechanics." Trans. Instn Min. Metall. (Sect.A) 101, 149-158.

13. "First Order Second Moment method." Wikipedia. [Online] Wikipedia, December 3, 2019. https://en.wikipedia.org/wiki/First-order_second-moment_method.

14. "Shapiro"- Wilk Test. Wikipedia. [Online] Wikipedia Foundation, October 28, 2019. https://en.wikipedia.org/wiki/Shapiro\%E2\%80\%93Wilk_test.

15. "Hydraulic conductivity and intrinsic permeability of fissured and fractured rocks" (1981). Developments in water science, 396- 472.

16. Dahal RK, Hasegawa S, Masuda T, Yamanaka M. "Roadside slope failures in nepal during torrential rainfall and their mitigation”. Disaster Mitig Debris Flows, Slope Fail Landslides. 2006;503-14.

17. Zhou A, Li C-Q, Huang J. "Failure analysis of an infinite unsaturated soil slope." Proc Inst Civ Eng - Geotech Eng. 2016;169(5):410-4 